\title{
Numerical Simulation of the Overtopping-Ramp Design of a Multistage Overtopping Wave Energy Breakwater Hybrid Device
}

\author{
M. A. Mustapa, O. B. Yaakob, Yasser M. Ahmed
}

\begin{abstract}
One type of wave energy converter is based on the overtopping concept. An example of such device is the multi-reservoir Sea Slot-Cone Generator (SSG) which is based on a simple flat breakwater ramp design. Although it is capable of functioning as both a wave-breaker and wave energy harvester, the SSG still suffers from low performance with 38 percent hydraulic efficiency. This paper presents a numerical study to further improve the performance. The present research work considers the use of convex, concave, $V$-shape and bridge $V$-shapes front ramp designs. The overtopping phenomena were simulated using Computational Fluid Dynamic (CFD) software known as Flow3D. The results are presented in the form of mean overtopping discharge and expected power output for each of the three reservoirs. At the end of the study, the final results showed that the highest potential power output is given by the V-Shapes design with 67 percent $(56.9 \mathrm{~kW})$ improvement compared to current existing SSG device, which recorded $(34.1 \mathrm{~kW})$ at the wave height of 2.80 meters and a wave period of 9.3 seconds.
\end{abstract}

Index Terms: Ocean Energy, Marine Renewable Energy, Wave Energy Converter, Overtopping Device, Computational Fluid Dynamic (CFD)

\section{NOMENCLATURE}

SSG Sea Slot Cone Generator

WEC Wave Energy Converter

oWC Oscillating Water Column

OWSC Oscillating Wave Surge Converter

PP Power Pyramid

CFD Computational Fluid Dynamic

VOF Volume of Fluid

NS Navier-Stokes Equations

RANS Reynolds Averaging of the Navier-Stokes

$\eta_{H y d}^{s s}$ Overtopping Device Efficiency

$P_{\text {Hyd }}$ Hydraulic Power or Potential Energy Store in Reservoir $P_{\text {wave }}$ Wave Power

$\rho$ Density of Water
Revised Manuscript Received on November 05, 2019.

M. A. Mustapa, Marine Engineering Technology, Universiti Kuala Lumpur/ Malaysian Institute of Marine Engineering Technology, Lumut, Perak.

O. B. Yaakob, Mechanical Engineering, Universiti Teknologi Malaysia/

Marine Technology Center, Skudai, Malaysia.

Yasser M. Ahmed, Faculty of Engineering, Alexandria University, Alexandria, Egypt. $g$ Gravitational Acceleration

$H_{r m s, 0}$ Root Mean Square for Wave Height

$\left[C_{g 0}\right]_{\bar{T}}$ Offshore Group Velocity

$\mathrm{H}_{S}$ Significant Wave Height

$T_{e}$ Harmonic Average Wave Period

$\xi_{\text {op }}$ Breaker Parameter

$S_{\text {op }}$ Wave Steepness

$T_{p} \quad$ Wave Period, Peak Period of the Wave Spectrum

$\alpha$ Slope Angle

$Q_{b}$ Dimensionless Overtopping Discharge for Breaking Waves

$Q_{n}$ Dimensionless Overtopping Discharge for

Non-Breaking Waves

$q_{o v}$ Mean Overtopping Discharge per unit width

$R_{c}$ Wave Crest Height for Reservoir

$H_{m 0, t}$ Water Depth at Structure Toe

$L_{0 p} \quad$ Wave Length at Structure Toe

$d_{r}$ Vertical Ramp Cut

$h$ Water Depth

\section{INTRODUCTION}

Ocean renewable energy could provide a significant supply to world electricity demands. This energy can be sourced from ocean waves, tidal current, tidal barrage, as well as thermal and salinity gradients. Ocean wave energy can be harvested using several wave energy extraction concepts such as overtopping devices, oscillating water column (OWC), attenuator devices, oscillating wave surge converter (OWSC) and point absorber.

One example of a device used to harvest wave energy using overtopping concept is the Sea Slot-Cone Generator [1][2]. The main advantage of choosing this overtopping concept against other wave energy extraction concepts is illustrated in the cost-sharing benefit. Since adapting integration between the breakwater and the wave energy converter (WEC), several costs including manufacturing, installation, and maintenance costs can be shared. The traditional coastal breakwater design has concentrated more on dissipating the incoming wave energy by breaking rather than extracting the energy for electricity generation. The breakwater is integrated with the WEC device, with an additional reservoir unit placed on top of the breakwater structure. As a wave starts to climb and later break due to shallowing, the remaining wave that retracts to the ocean will start filling the reservoir. 


\section{Numerical Simulation of the Overtopping-Ramp Design of a Multistage Overtopping Wave Energy Breakwater Hybrid Device}

This will lead to a Reduction of reflected waves and catch the overtopping wave in the reservoir for energy generation.

In 2002, the SSG device was first invented [3]. The concept was initially inspired by the previous invention of the Power Pyramid (PP) [4]. Physically, the SSG device is a multistage device consisting of multi-stage reservoirs. These overlapping reservoirs have the potential to extract wave energy from various levels depending on the wave condition. The water that is stored inside the reservoir is kept in the form of a potential energy and later used to drive the hydro turbine for electricity production. At present, no development of prototype in real world application has been recorded.

The original study was carried out using experimental work to find the optimum geometries, in order to improve the mean overtopping discharge on each reservoir [1]. Further studies were carried out using single-use on conventional SSG design with an analysis conducted on wave direction and spreading effect [5], an effect of the horizontal distance between reservoir [6], wave loading act on SSG [7] and lastly, optimisation of geometry for Hanstholm Port [8].

This presents paper is carried out to find the optimum ramp design of the overtopping device. The main purpose is to increase device efficiency. This present study will concentrate on the shapes of the ramp wave ramp to improve overtopping performance. The proposed ramp design was simulated numerically using Computational Fluid Dynamics (CFD) software. Thus, this paper will show the mean overtopping discharge and device efficiency.

\section{LITERATURE REVIEW}

\section{Overtopping Device Performance}

The efficiency of a device for the overtopping concept can be determined by the function of device efficiency $\eta_{H y d}^{S S}$, wave power $P_{\text {wave }}$ and hydraulic power $P_{\text {Hyd }}$ as defined in Equation 1.

$\eta_{\text {Hyd }}^{s S}=\frac{P_{\text {Hyd }}}{P_{\text {wave }}}$

\section{The Wave Power}

For deepwater application, the mean sea-state power recorded at the ramp of the overtopping structure can be measured using;

$$
P_{\text {wave }}=\frac{1}{8} \rho g H_{r m s, 0}^{2} \cdot\left[C_{g 0}\right]_{\bar{T}}
$$

where;

deepwater significant wave height $H_{s_{0}, 0}$, whether spectrally or statistically defined, is approximately $\sqrt{2} H_{r m s_{0}, 0}$, it will give [1]:

$$
P_{\text {wave }}=\frac{\rho g^{2} H_{s, 0}^{2} \cdot T_{e}}{64 \pi}
$$

This Equation 4 is valid starts from wave propagation phenomena until the wave begins to break.

\section{Non-Dimensional Overtopping Discharge}

According to Van der Meer, the equation of non-dimensional overtopping discharge $Q$ can be divided into two forms. The equations include $Q_{n}$ for non-breaking waves and $Q_{b}$ for breaking waves [9]. The phenomena of a non-breaking and breaking wave can be expressed using breaker parameter, $\xi_{o p}$. For non-breaking waves, $\xi_{o p}$ is higher than 2 and for breaking waves, $\xi_{o p}$ is less than 2 . The breaker parameter equation is;

$$
\xi_{\text {op }}=\frac{\tan _{\alpha}}{\sqrt{S_{\text {op }}}}=\frac{\tan _{\alpha}}{\sqrt{2 \pi \cdot H_{S} /\left(g \cdot T_{p}{ }^{2}\right)}}
$$

where;

$\alpha$ represents slope angle,

$S_{\text {op }}$ represents as wave steepness,

$H_{S}$ represents significant wave height, and

$T_{p}$ represents wave period, a peak period of the wave spectrum,

Wave steepness equation is defined in Equation 6;

$S_{o p}=\frac{2 \pi \cdot H_{s}}{\left(g \cdot T_{p}{ }^{2}\right)}$

For breaking waves, the equation for dimensionless overtopping discharge, $Q_{b}$ is;

$Q_{b}=\frac{q}{\sqrt{g \cdot H_{s}{ }^{3}}} \cdot \frac{\sqrt{S_{o p}}}{\sqrt{\tan _{\alpha}}}$

For non-breaking waves, the equation for dimensionless overtopping discharge, $Q_{n}$ is;

$Q_{b}=\frac{q}{\sqrt{g \cdot H_{s}{ }^{3}}}$

$\left[C_{g 0}\right]_{\bar{T}}$ represents as the offshore group velocity calculated at the mean period of $\mathrm{T}$, and

$H_{r m s, 0}$ represents the root mean square for wave height.

$$
\left[C_{g 0}\right]_{\bar{T} \equiv T_{e}}=\frac{g T_{e}}{4 \pi}
$$

In Equation 3, the harmonic average wave period $T_{e}$ is employed for $\bar{T}$; the latter is about 1.1 the peak period $T_{p}$ and is calculated as the ratio between the spectral moment of order -1 and the area of the power spectrum. By noting that the

where;

$q$ represents as mean overtopping discharge, $\left(\mathrm{m}^{\wedge} 3 / \mathrm{s} / \mathrm{m}\right)$

\section{The Hydraulic Power}

The most important result to determine WEC device performance is known as total hydraulic power or overtopping power. The result is calculated by considering the opening width of the overtopping 
structure and is calculated using [1];

$P_{\text {hyd }}=\sum_{j=1}^{N_{\text {Res. }}} \rho g q_{o v, j} R_{c, j}$

where;

$N_{\text {Res. }}$ represent the total number of reservoirs in SSG device, $R_{c_{s} j}$ represents wave crest height for the reservoir, measure vertically from the mean water level to

$j$ th-reservoir front peak, refer to Error! Reference source not found., and

$q_{o v, j}$ represent the mean overtopping discharge per unit width, entering the $j$ th-reservoir.

\section{Previous Study on SSG Device}

Since its invention, only a few studies have been carried out to improve the existing SSG device design. The improvement process can be divided into three categories.

\section{Reservoir Height}

The first parameter that may affect the result of mean overtopping discharge $q_{o v, j}$ is the SSG ramp height as conducted by Kofoed (2005) [1]. This reservoir height is present in $R_{C, 1}, R_{C, 2}, R_{C, 3}$, as shown in Error! Reference source not found. and Error! Reference source not found. for the side and isometric view respectively.

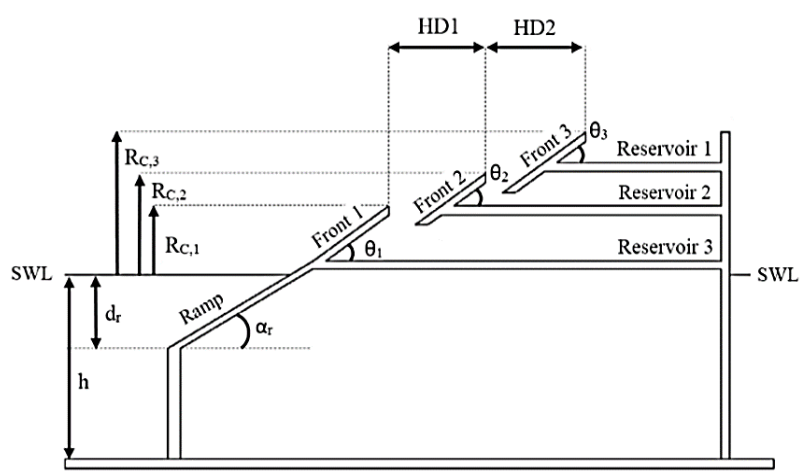

Fig. 1 Scheme of a SSG (Side view)

Kofoed has revealed that reducing SSG ramp height may reduce the height of reservoir freeboard and thus may significantly increase the overtopping discharge [1]. This finding has been further proven by Waal and Van der Meer [10]. A similar effect may also be influenced by changes in water depth at SSG toe, $H_{m 0, t}$. A previous study conducted by Kofoed [1] and Margheritini [5] has revealed that the increase of $H_{m 0, t}$ in front of the SSG toe may increase the value of $q_{o v, j}$. The result may be the opposite, especially at the first and second reservoir as the $H_{m 0, t}$ value becomes larger. The spectral significant wave height at the SSG toe, $H_{m 0, t}$ is given in Equation 10:

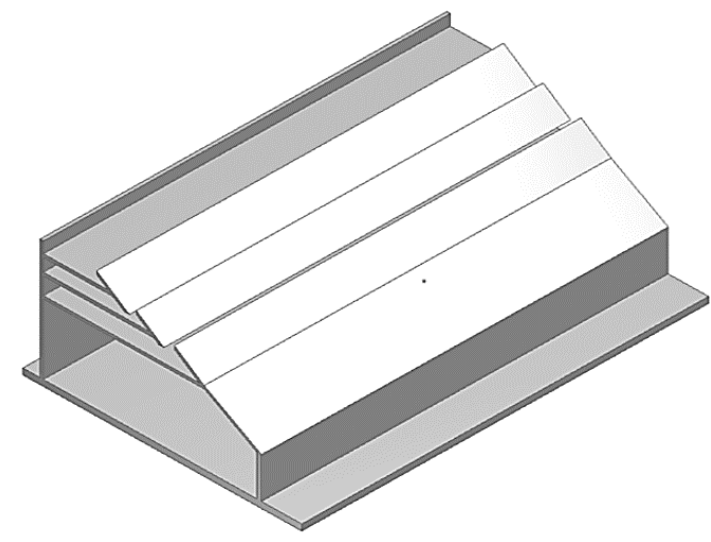

Fig. 2 Scheme of SSG design (Isometric view)

$s_{0 p}=\frac{H_{0 n, \varepsilon}}{L_{0 p}}=\frac{H_{m e, k}}{g T_{p}^{2} / 2 \pi}$

The $L_{0 p}$ is defined as the wavelength at the structure toe, measured in meters. Since the $H_{m 0, t}$ value is affected by the wave steepness $s_{0 p}$ value, previous studies conducted using a 35-degree angle of the front SSG plate and the ramp has allowed waves to dissipate gently through surging waves breaking. Although theoretically it improves the overtopping results, in real-world conditions it does not have much influence on the wave run-up process as studied by De Waal [10] and later on the overtopping phenomena as mentioned by Van der Meer [11].

\section{Ramp Cut}

The second most important parameter that may affect the mean overtopping discharge is the ramp cut. A study conducted by Kofoed (2005) has proven that in conditions where the front ramp is vertically cut below the mean water level, represented as $d_{r}$ in Error! Reference source not found., the wave reflection effect may become apparent and later influenced by reducing the mean wave overtopping discharge. These phenomena happen as incoming waves will tend to break earlier before passing through all three reservoirs. Kofoed has also mentioned that the mean overtopping discharge result relies on changes in water depth proportionally. Comparison between both vertical and no vertical ramps $\left(d_{r} / h=1\right)$ shows that non-vertical ramp gives better performance since it provides a maximum influx effect due to dismissal of wave reflection. This is supported by model testing results conducted by Kofoed [1] which shows a 5 percent improvement on the hydraulic efficiency result, measured from both non-vertical $\operatorname{ramp}\left(d_{r} / h=1\right)$ and vertical $\left(d_{r} / h=0.375\right)$ cases.

\section{Ramp Angle}

The final parameter that may cause changes in the result of mean overtopping discharge is the structure ramp angle, $\alpha_{r}$ as illustrated in Error! Reference source not found.. Since it provides the first contact with the incoming wave, this ramp structure is capable to lower the incoming wave force which occurs as the water 


\section{Numerical Simulation of the Overtopping-Ramp Design of a Multistage Overtopping Wave Energy Breakwater Hybrid Device}

depth at the ramp structure begins to reduce. This reduction in water depth happens in proportion to the increase in ramp slope angle. This angle plays an important role in determining the type of wave breaking, either spilling, plunging or surging. Kofoed has come out with a model scale study on three different ramp angles consisting of 19,30 and 35 degrees [1]. He has concluded that 19 degree is the most preferred angle with 4 percent enhancement in hydraulic efficiency. However, this angle leads to plunging waves which may cause a heavy slamming effect on the front face of the structure. Therefore Kofoed has suggested 35 degrees as the appropriate angle to optimally resist the incoming wave and at the same time help improve the wave run-up for overtopping proposes as previously stated by LeMéhauté [12] and Kofoed [3].

\section{Overtopping-Ramp Design Overview}

A current existing overtopping device adapted the use of simple flat horizontal ramp design as used by the previous studies conducted by Kofoed [1], Vicinanza [13][14], and Margeratini [6]. The main reason for choosing this flat design is due to its simple shape while maintaining the functionality to both breaks the waves and harness the wave energy.

\section{PURPOSE OF THE PRESENT WORK}

The main purpose of the present work is to study and find the most optimum ramp design of the overtopping device. The dimension of the model used was scaled down from a prototype at 1:15 ratio using the Froude scaling method. For this study, the basis dimension used for SSG device was taken based on Kofoed [1]. The crest freeboard height for each reservoir was placed at a constant height. It is presented as Rc3, Rc2 and Rc1, with a height of 0.15 meter, 0.22 meter and 0.31 respectively, given in model scale value. Each reservoir has a 0.029 meter opening gap for HD1 and HD2 as shown in Error! Reference source not found.. The ramp angle is 19 degrees. The reason of using 19 degrees for ramp structure angle is because the potential to produce 4 percent improvement in hydraulic efficiency compared to both 30 and 35 degrees, which are suitable for overtopping device with single reservoir application [3]. The opening width of the reservoir is 0.5 meters and the breakwater structure opening width is 4 meters wide. The full arrangement of both breakwater and the overtopping device is given in Fig.

The water depth of 0.4 meters was used during this study. Fig illustrates the basis model scale of SSG dimensions, taken from Kofoed (2005).

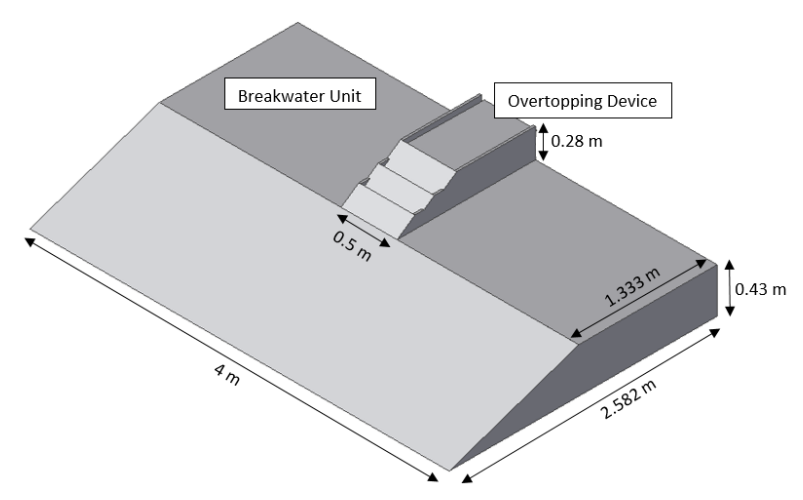

Fig. 3 WEC-Breakwater configuration

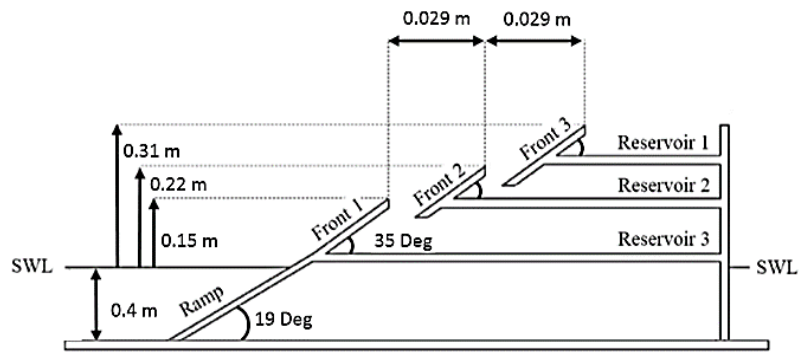

Fig. 4 Basis SSG device dimension (model scale values)

The dimensions of the other four proposed ramp designs are given in Figure 6 to 9. To enable comparison of performance, the proposed designs used the same reservoir freeboards (Rc1, Rc2 and Rc3) and opening gaps (HD1 and HD2) as used by the original SSG device as given in Fig.

For this study, three dimensional CFD simulation method was chosen and the Flow-3D software was selected. Flow-3D implements a technique called Volume of Fluid (VOF). The main purpose is to allow free-surface tracking. This software provides a multi-physics solver that allows for a wide range of flow problems. The fundamental equations behind this software for flow dynamics are the conservation of mass and momentum. The governing model equations are discretized in space with a finite difference/finite volume technique, using Eulerian structured grids with a staggered mesh topology. A cut-cell method is used for obstacle representation, defining a cell-based area and volume fractions which are directly incorporated in the conservation equations of mass and momentum [15].

The arrangement of the model and the flume size used are different compared to the study carried out by Kofoed [1]. The first step requires us to conduct a grid-dependent study. This procedure is needed to find the most optimum mesh element numbers in the simulation. For this study, both wave height and wave period were set to 0.15 meter and 1.8 seconds respectively based on model scale values. The simulation work was carried out using linear wave function model and, only one overtopping wave was considered. The gap between the flume sidewall and the breakwater is set to 0 meters as initial distance.

As the 3-Dimensional study was conducted, the effect of the flume side-wall correspond to the results of the mean overtopping discharge was first studied. This helps avoid any flow interference that may be created within the gap between the flume side-wall and the breakwater as shown in Error! Reference source not found.. A long clear region was provided in front of the breakwater structure to allow full development of the incoming waves before it reaches to the breakwater toe area. In addition, this also helps to avoid interference between the incoming and reflected waves. At the back of the breakwater unit, there is a passive slope. This slope helps to absorb the remaining waves from reflecting back to the breakwater structure. Reflecting waves may change the characteristics of the incoming wave as it starts to collide with each other. This may cause the development of a standing wave. The phenomena occur as two waves with similar frequency collide with each other while 
travelling in different directions. If the wave crest and trough pass through each other, it will produce destructive interference. This additional distance allows four incoming waves to travel along the flume while the simulation is running.

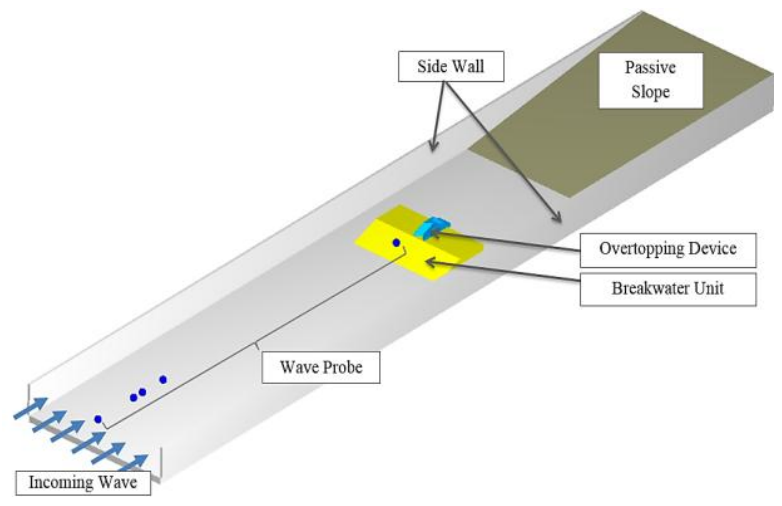

Fig. 5 Full arrangement for CFD simulation

Finally, an additional breakwater unit with 4 meter width was put under the overtopping unit with an optimum gap between the flume and the breakwater sidewall. This arrangement was used to mimic an actual condition where the overtopping device will be operating. In this study, only linear waves were used.

To further understand the consequences of the ramp design on the mean overtopping discharge, three sets of wave conditions were used, similar to Kofoed [1]. The significant wave heights were varied from $2.25 \mathrm{~m}, 2.8 \mathrm{~m}$ and $3.3 \mathrm{~m}$, and the wave period varied from $7.9 \mathrm{~s}, 9.3 \mathrm{~s}$ and $10.6 \mathrm{~s}$ respectively. Table 1 shows the wave conditions used in this study with both normal (off-shore wave condition) and realised (wave condition measured at the toe of the ramp structure) wave conditions as illustrates in Error! Reference source not found.

Table. 1 Wave conditions generated in simulation (full-scale values)

\begin{tabular}{|l|l|l|l|}
\hline Wave Condition & $\mathbf{2 - 3}$ & $\mathbf{3 - 4}$ & $\mathbf{4 - 5}$ \\
\hline Hs $(\mathrm{m})$ & 2.50 & 3.50 & 4.50 \\
\hline Tp $(\mathrm{s})$ & 7.9 & 9.3 & 10.6 \\
\hline Hs, realized $(\mathrm{m})$ & 2.25 & 2.80 & 3.35 \\
\hline Pwave, realized $(\mathrm{kW} / \mathrm{m})$ & 17.1 & 31.2 & 50.9 \\
\hline
\end{tabular}

In this research, the output result is in the form of the overtopping rates for individual reservoirs, $q_{n^{*}}$ Using this result, the potential energy of storing water inside the reservoirs can individually be calculated using Equation 9. Later, total power was calculated by summing up all potential energy from all three stages of the reservoir. The result was later compared with those from the original SSG design.

\section{New Overtopping-Ramp Designs}

Since the flat horizontal ramp design gives a small overtopping device efficiency, several designs including $\mathrm{V}$-shape, bridge $\mathrm{V}$-shape, concave and convex were proposed and used in this study as shown in Figure 6, 7, 8 and 9 respectively. The use of the new design replacing the flat horizontal ramp design is aimed at improving the efficiency of the overtopping device by capturing more water for single wave propagation. This is possible by manipulating the incoming flow of the waves. The flow pattern may change significantly corresponding to the ramp design. Since the main goal of the overtopping device is to lift the water higher, the ramp design is important to enable the incoming waves to flow in one desired direction. Thus, several designs including $\mathrm{V}$-shape, bridge $\mathrm{V}$-shape, concave and convex were proposed and used in this study as shown in Figures 6, 7, 8 and 9 respectively.

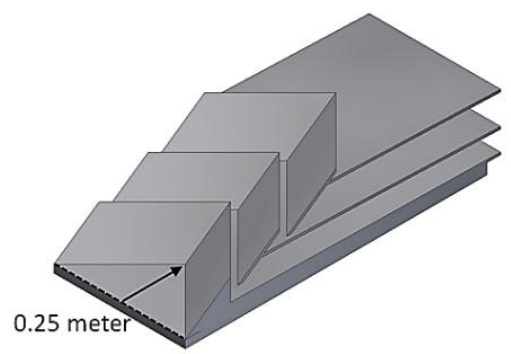

Fig. 6 Isometric view of V-shape (model scale value)

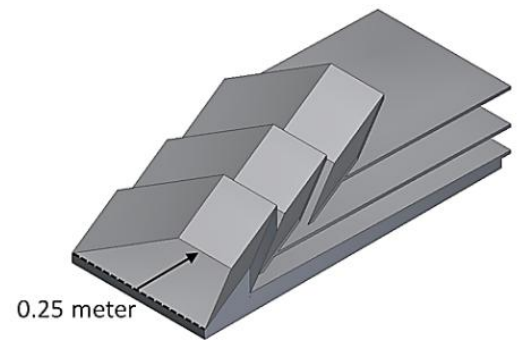

Fig. 7 Isometric view of Bridge V-shape (model scale value)

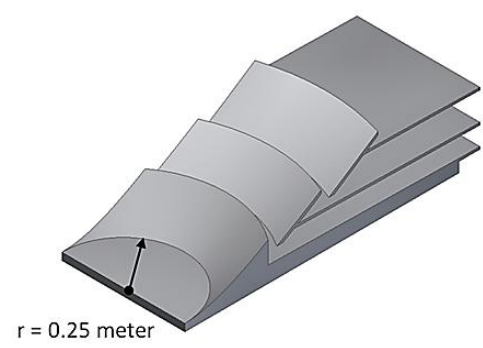

Fig. 8 Isometric view of Concave (model scale value)

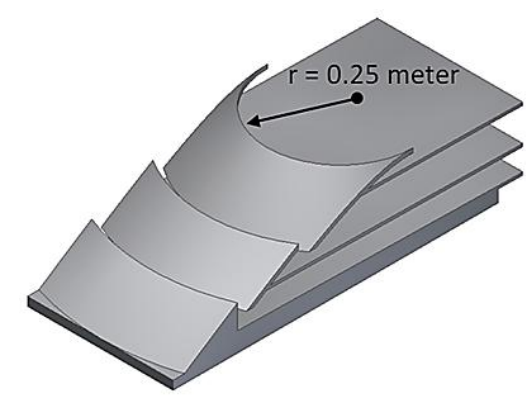

Fig. 9 Isometric view of Convex (model scale value) 


\section{Numerical Simulation of the Overtopping-Ramp Design of a Multistage Overtopping Wave Energy Breakwater Hybrid Device}

\section{CFD SIMULATIONS}

The numerical study was conducted using Flow-3D software. This software implemented full 3D Navier-Stokes (NS) equations. It works as a basis to model the conservation of mass and momentum in solving a wave interaction problem. In addition, Flow-3D used Reynolds Averaging of the Navier-Stokes (RANS) equation to solve the Navier Stokes Equation. In this research, the case involves solving the free surface problem. Thus, the Volume-of-Fluid (VOF) technique is used to track the free surface interaction effect. In the VOF technique, the VOF function is presented as $\mathrm{F}$ $(\mathrm{x}, \mathrm{y}, \mathrm{z}, \mathrm{t})$ in representing the fluid configurations.

When defining the interaction between waves and fixed structure in a wave flume, the initial condition of the fluid is set to sit at rest in a whole computational domain. At every corner of the computational domain, a boundary condition was initially specified. These boundary conditions may present as external factors that act differently depending on the specific flow problem. In this study, the input domain at the incoming wave location is set to wave boundary type. Fig shows the input boundaries assigned at every corner of the computational domain where $\mathrm{WV}, \mathrm{W}, \mathrm{P}, \mathrm{C}$ and $\mathrm{O}$ represent as a wave, wall, specified pressure, continuative and outflow respectively.

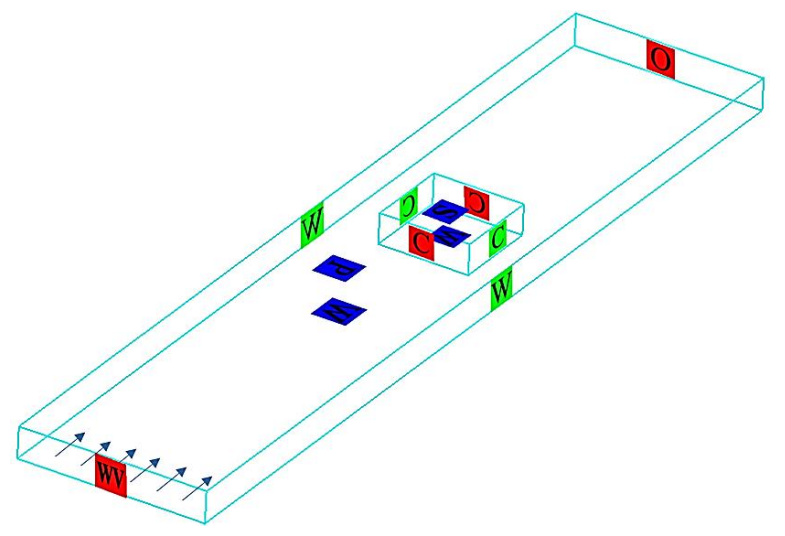

Fig. 11 Boundaries for numerical simulation (Isometric View)

For this study, the number of a grid line size is fixed to four. Each grid line controls the mesh quality. The main purpose of using four different grid-line sizes was to reduce the time taken during simulation. The smaller the grid-line size, the longer it will take for the simulation to finish. Grid-line also controls the quality of the mesh. The smaller the size, the better the mesh is. Thus, in order to find the optimum size for the grid-line, a grid-dependent study was first conducted.

For this study, the outer grid line has a size of 0.044 meters. The second inner grid has a size of 0.022 meters followed by the third inner with 0.011 meters. Finally, the most optimum grid line located on the overtopping device has a size of 0.0055 meters. The optimum size is taken based on the results obtained during the grid-dependent study. The difference in grid line sizes is shown in Fig.

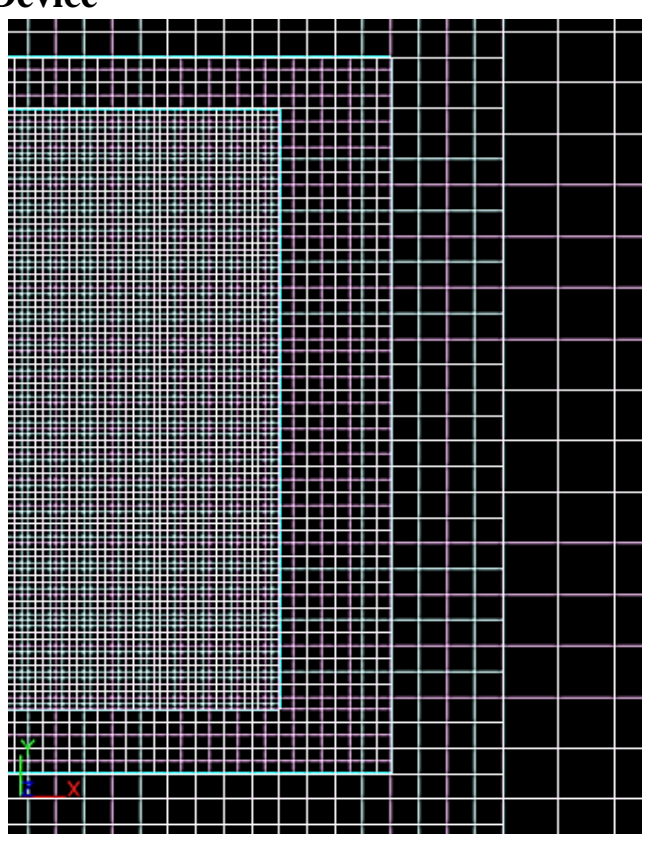

Fig. 11 Four different grid line size for CFD simulation

Using an optimum grid line size, further study was conducted on the effect of the sidewall on the mean overtopping discharge result. This procedure was carried out to find the most optimum distance between the flume wall and the overtopping device. This may help to avoid flow interference. However, a larger gap will cause simulation to take longer time to finish since it requires additional size in the computational domain. If the distance is too large, the simulation will take a longer time to finish since it requires additional size in the computational domain.

In this study, fourteen incoming waves were used. The first four incoming linear waves were neglected since the waves were not fully developed yet. Thus, data were recorded starting from the fifth wave crest. This is the minimum number required to collect enough water in the reservoir to determine the overtopping rate as suggested by Kofoed [3]. In order to get the exact wave characteristics during CFD simulation, the first set of simulation work was conducted using an empty tank without the breakwater and overtopping device model. The location of interest during the overtopping study was at the toe of breakwater [16]. Due to energy losses in waves while travelling the distance before reaching the breakwater, the wave conditions obtained at the breakwater toe was less than the input data. When the results of the wave heights and wave periods at the breakwater toe give the desired wave characteristic as shown in Table, the testing of the various ramp shapes was carried out.

\section{RESULTS AND DISCUSSION}

\section{Grid Dependent Study}

Fig shows the interaction of incoming waves with 0.15 meter wave height and $1.8 \mathrm{sec}$ wave period on the V-Shape structure, where the water starts to fill the reservoirs as the wave begin to retract back to the sea.

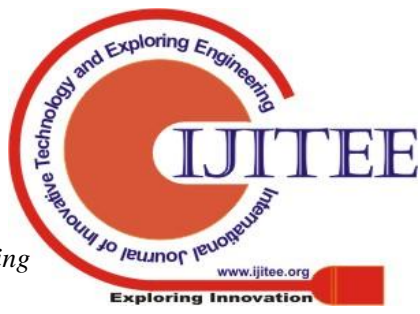




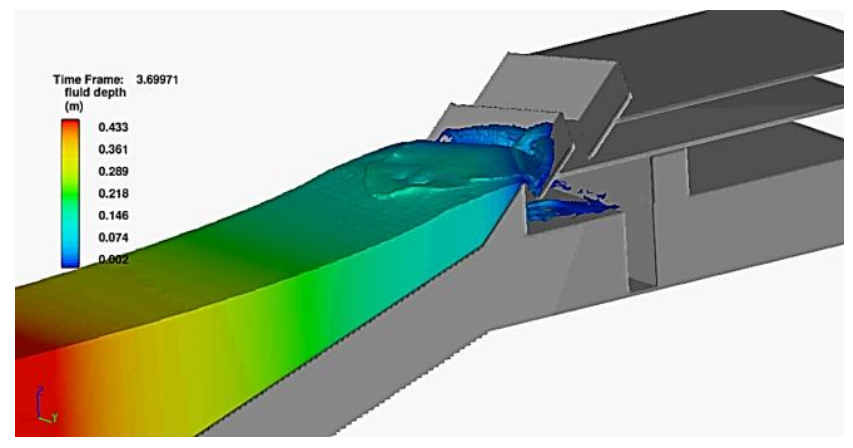

Fig. 12 Interaction of incoming wave with V-Shape design

Figure 13 illustrates the effect of increasing mesh elements on mean overtopping discharge for various ramp shapes. The mean overtopping discharge was calculated by summing up the entire water stored inside the reservoir divided by the time duration. As the number of mesh element becomes higher, the mesh quality becomes finer and takes longer time to end the simulation. Based on the results of the grid-dependent study, the most optimum mesh element number for SSG, concave, convex, $\mathrm{V}$-shape and bridge $\mathrm{V}$-shape design was 5.68, 7.3 9.5, 5.68 and 5.68 million respectively. The result given is expected since the complex designs such as concave and convex need more elements in order to produce smoother results.

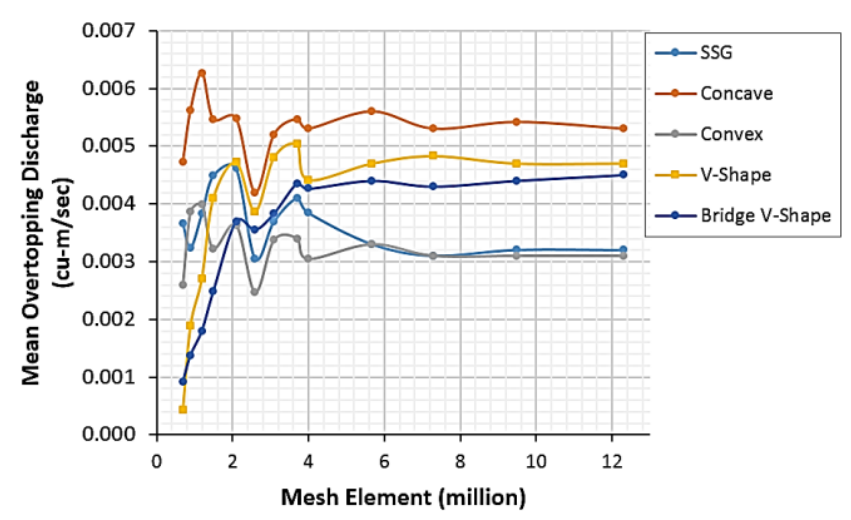

Fig. 13 Computational model result at different mesh element number

Fi shows the example of mesh quality on the V-Shape ramp design using 5.68 million of mesh element.

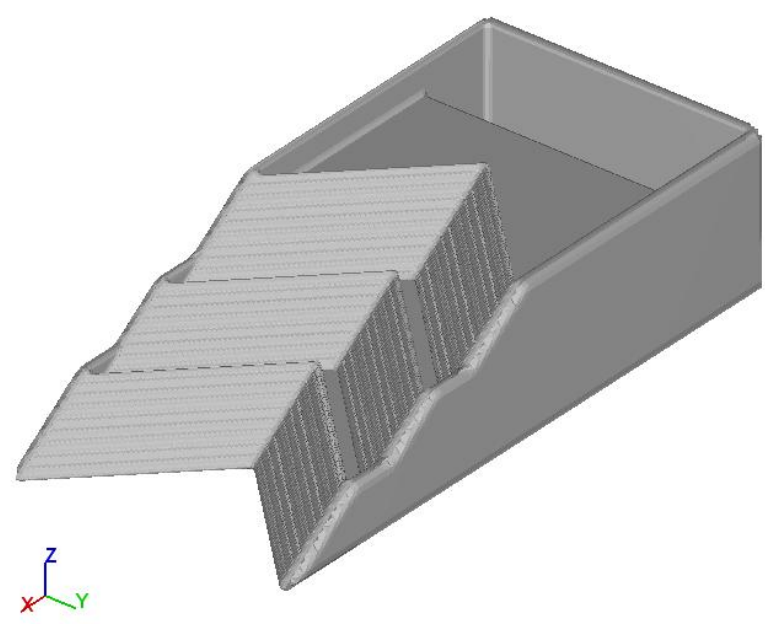

Fig. 14 Optimum mesh element on V-Shape design

\section{Wall Effects}

The second test was carried out using a function of the linear wave. Single incoming wave with a wave height of 0.187 meters and a wave period of 2.4 seconds were considered. The SSG model was set up using an optimum grid line arrangement. Fi shows a trend of the mean overtopping discharge correspond to a gap between flume sidewall and the breakwater as graphically illustrated in Error! Reference source not found. As the distance is narrow, the flow which was closer to the sidewall will react more quickly. As a result, flow near the sidewall will drastically change in pressure gradient compared to the flow located in the middle of the flume. This happens due to the sidewall boundary which was bounded by the no-slip condition [17]. Thus, high turbulence flow generated near to the flume sidewalls has a high tendency to produce more dissipation corresponding to time as it reaches the flume centerline. This happens in a wider channel. Thus, as the distance getting wider, the mean overtopping discharge will start to produce consistent results. Based on the results shown in Fi, optimum distances between the flume and breakwater sidewall is at 1.38 meters at model scale. The result is acceptable since the final five distance of $1.38 \mathrm{~m}, 1.65 \mathrm{~m}, 1.91 \mathrm{~m}, 2.17 \mathrm{~m}$ and $2.44 \mathrm{~m}$ produce less than 5 percent difference in the mean overtopping discharge result.

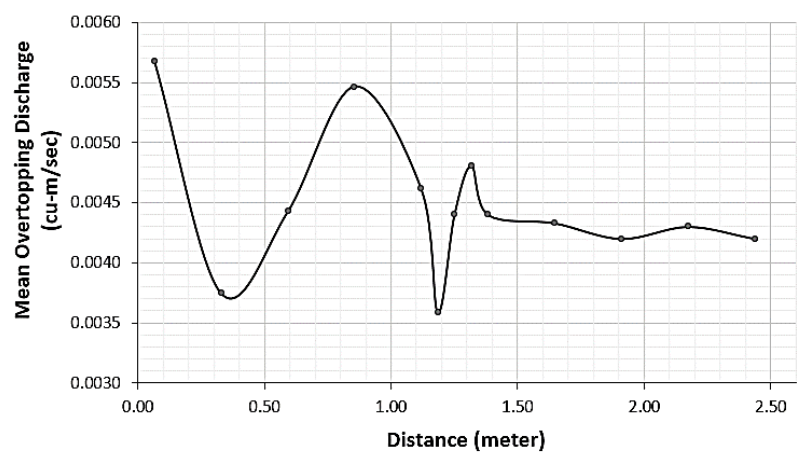

Fig. 15 Interference effect reduced as flume and breakwater sidewall distance increase (Model Scale Value)

\section{Ramp Design Effects}

The final stage of the research was conducted using optimum dimensions based on both grid dependency and wall effect studies. The use of different ramp designs is expected to improve the existing flat horizontal design as used by the SSG. Fig shows the mean overtopping discharge obtained after the simulation. The results are separated into three different reservoir levels. It consists of lower, middle and higher reservoirs which represent as R3, R2 and R1 respectively. 


\section{Numerical Simulation of the Overtopping-Ramp Design of a Multistage Overtopping Wave Energy Breakwater Hybrid Device}

a)

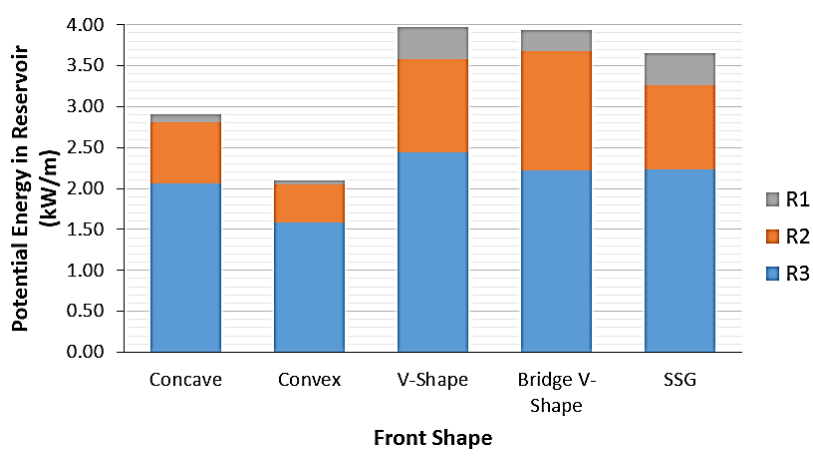

b)

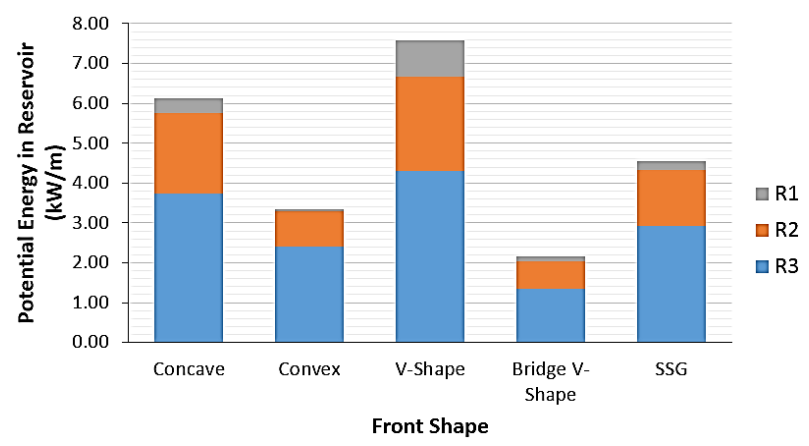

c)

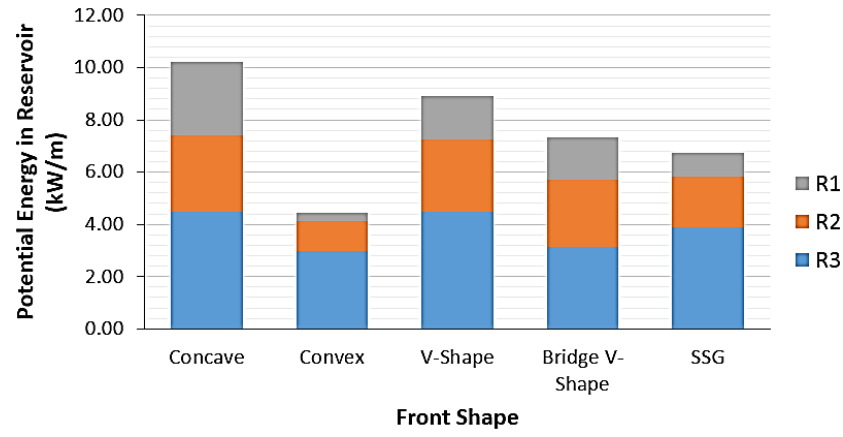

Fig. 16 Comparison of Potential Energy store (Full-Scale Values) at wave condition of, a) (2-3), b) (3-4), c) (4-5)

Based on (2-3) wave condition as given in Table, both $\mathrm{V}$-shape and Bridge V-shape show almost 9 and 8 percent improvement respectively. Both results were compared to the conventional SSG design. The V-shape design is capable of producing $29.8 \mathrm{~kW}(2.27 \mathrm{MJ})$ of potential energy compared to SSG with only $27.4 \mathrm{~kW}(2.09 \mathrm{MJ})$. On the other hand, both concave and convex ramp produced lower outputs. For wave condition (3-4), the result surprisingly changed. The use of V-shape and Concave shapes resulted in nearly 67 and 35 percent of improvement compared to the SSG design. The $\mathrm{V}$-shape design manages to produce $56.9 \mathrm{~kW}$ (4.33 MJ) compared to $34.1 \mathrm{~kW}(2.6 \mathrm{MJ})$ produced by the SSG shape. But, both convex and Bridge $\mathrm{V}$-shape suffer from negative improvement. When the wave conditions become much rougher at wave condition (4-5), positive improvement is recorded by all three designs consisting of concave, $\mathrm{V}$-shape and bridge $\mathrm{V}$-shape with 52, 33 and 9 percent improvement. The most significant improvement is achieved by the concave shape ramp with $76.6 \mathrm{~kW}$ (5.84 MJ) of potential energy with respect to $50.5 \mathrm{~kW}(3.85 \mathrm{MJ})$ produced by SSG. Table shows the final results in full scale for mean overtopping discharge, hydraulic power and efficiency.

Table. 2 Results of performing simulation work, given in full-scale value

\begin{tabular}{|l|c|c|c|c|c|c|c|c|c|}
\hline Design & $\begin{array}{c}\text { Wave } \\
\text { Cond. }\end{array}$ & $\begin{array}{c}\mathbf{q} \mathbf{3} \\
\left(\mathbf{m}^{\wedge} \mathbf{3} / \mathbf{s} / \mathbf{m}\right)\end{array}$ & $\begin{array}{c}\mathbf{q} \mathbf{2} \\
\left(\mathbf{m}^{\wedge} \mathbf{3} / \mathbf{s} / \mathbf{m}\right)\end{array}$ & $\begin{array}{c}\mathbf{q} \mathbf{1} \\
\left(\mathbf{m}^{\wedge} \mathbf{3} / \mathbf{s} / \mathbf{m}\right)\end{array}$ & $\begin{array}{c}\mathbf{P 3} \\
(\mathbf{k W} / \mathbf{m})\end{array}$ & $\begin{array}{c}\mathbf{P 2} \\
(\mathbf{k} \mathbf{W} / \mathbf{m})\end{array}$ & $\begin{array}{c}\mathbf{P 1} \\
(\mathbf{k W} / \mathbf{m})\end{array}$ & $\begin{array}{c}\text { Ptotal } \\
(\mathbf{k W} / \mathbf{m})\end{array}$ & $\begin{array}{c}\text { eff. } \\
(-)\end{array}$ \\
\hline Concave & $2-3$ & 0.0932 & 0.0234 & 0.0020 & 2.06 & 0.76 & 0.09 & 2.91 & 0.17 \\
& $3-4$ & 0.1695 & 0.0626 & 0.0081 & 3.74 & 2.03 & 0.37 & 6.14 & 0.20 \\
& $4-5$ & 0.2028 & 0.0901 & 0.0620 & 4.48 & 2.92 & 2.83 & 10.22 & 0.20 \\
\hline Convex & $2-3$ & 0.0721 & 0.0141 & 0.0010 & 1.59 & 0.46 & 0.05 & 2.09 & 0.12 \\
& $3-4$ & 0.1088 & 0.0274 & 0.0009 & 2.40 & 0.89 & 0.04 & 3.33 & 0.11 \\
& $4-5$ & 0.1354 & 0.0354 & 0.0067 & 2.99 & 1.15 & 0.31 & 4.44 & 0.09 \\
\hline V-shape & $2-3$ & 0.1108 & 0.0351 & 0.0086 & 2.44 & 1.14 & 0.39 & 3.97 & 0.23 \\
& $3-4$ & 0.1948 & 0.0731 & 0.0201 & 4.30 & 2.37 & 0.92 & 7.58 & 0.24 \\
& $4-5$ & 0.2030 & 0.0854 & 0.0370 & 4.48 & 2.76 & 1.69 & 8.93 & 0.18 \\
\hline Bridge & $2-3$ & 0.1004 & 0.0452 & 0.0057 & 2.22 & 1.46 & 0.26 & 3.94 & 0.23 \\
V-shape & $3-4$ & 0.0607 & 0.0212 & 0.0030 & 1.34 & 0.69 & 0.13 & 2.16 & 0.07 \\
& $4-5$ & 0.1413 & 0.0797 & 0.0360 & 3.12 & 2.58 & 1.64 & 7.34 & 0.14 \\
\hline SSG & $2-3$ & 0.1009 & 0.0320 & 0.0086 & 2.23 & 1.04 & 0.39 & 3.65 & 0.21 \\
& $3-4$ & 0.1326 & 0.0435 & 0.0047 & 2.93 & 1.41 & 0.21 & 4.55 & 0.15 \\
& $4-5$ & 0.1765 & 0.0602 & 0.0195 & 3.90 & 1.95 & 0.89 & 6.74 & 0.13 \\
\hline
\end{tabular}

From the results, it shows that the ramp design with concentrated flow channel design such as concave, bridge $\mathrm{V}$-shape and V-shape has a high tendency to produce more overtopping than the flat horizontal ramp design. This happens as the incoming wave was first channelled into the narrow channel and the flow was later manipulated and directed to move in one desired direction. This happens when the leading wave speed begins to drop, the following wave will still moving faster than the leading wave. When both waves meet together, collision begins to occur and energy from the following wave will be transferred to the leading wave. This will improve the level of wave run-up on the overtopping device and significantly help to produce higher hydraulic power. The interaction of the incoming wave with the V-shape design is shown in Fig.

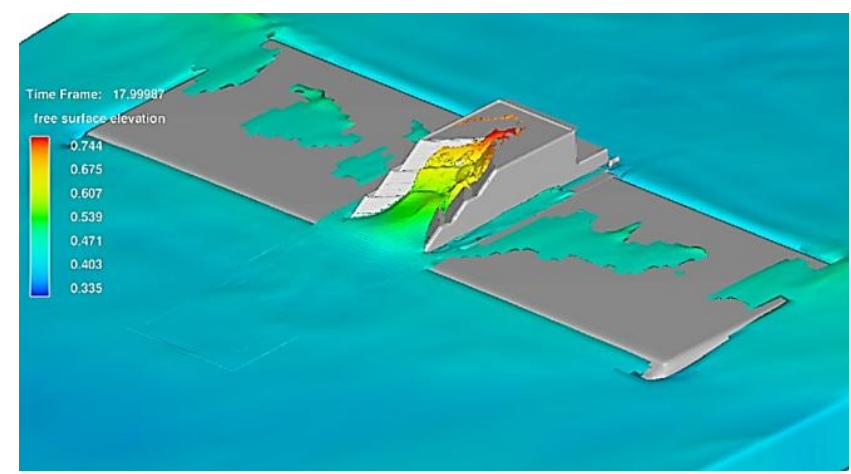

Fig. 17 Spilling effect occurs on V-Shape design at wave condition (4-5)

Although the $\mathrm{V}$-shape design performs better than other designs in term of device efficiency for both (2-3) and (3-4) wave conditions, it suffers from low device efficiency at higher wave condition of (4-5). This happens due to the over-spilling effect that is created by excess force during the run-up process. As the run-up waves go past the highest ramp (ramp 3), the run-up waves will splash high into the air and have less possibility of entering the highest reservoir (reservoir 1 as shown in Fig). This is shown in Fig. Thus, as shown in Table, at the highest reservoir, the mean overtopping discharge achieved by the V-shape 
design is much lower compared to the results given by the concave design although at both lower and middle reservoir it gives almost the same results. In other words, the $\mathrm{V}$-shape design has a huge advantage to operate in small (2-3) and moderate (3-4) wave condition, while is less efficient to operate at higher wave exceeding (4-5) wave condition.

\section{CONCLUSION}

A 3-Dimensional analysis of a ramp design for overtopping device has been carried out. The initial study on grid dependency was done in order to find an optimum mesh element needed for all five designs, resulting in different mesh element number for each design. Complex design requires additional numbers of a mesh element compared to a simple design. Optimum mesh number helps to improve the quality of simulation result in addition to reducing the time taken to end the simulation. The second study was carried out to find the effect of flume sidewall to mean overtopping discharge. Wave interference created between the flume and breakwater sidewall gives a negative effect to simulation results with a maximum percentage difference of 28 percent. The optimum distance needed to prevent interference between the flume and the breakwater sidewall is 1.38 meters at model scale value. The final study on the effect of the ramp design to device efficiency was carried out and the result shows a good improvement compared to the existing SSG design. The concentrated flow channel design shows an improvement in the overtopping device performance, especially when operating in both small and moderate wave conditions below 3.35 meter wave height. In this study, the V-shape design gives 67 percent improvement in hydraulic power relative to the existing SSG design. The $\mathrm{V}$-shape design manages to produce $7.58 \mathrm{~kW} / \mathrm{m}(56.9 \mathrm{~kW})$ of hydraulic power compared to $4.55 \mathrm{~kW} / \mathrm{m}(34.1 \mathrm{~kW})$ recorded by the SSG design, given in a full-scale value. At a condition where the wave height is greater the 3.35 meters, the most efficient shape is a concave design. This study is part of an on-going study to improve overtopping wave energy devices. Further work will be carried out to validate the results by carrying out models tests in a wave basin.

\section{ACKNOWLEDGEMENT}

Special thanks to Universiti Teknologi Malaysia (UTM), Universiti Kuala Lumpur (UniKL) and the Ministry of Higher Education Malaysia for funding this project under the Look East Policy Grant Vote No: 4L152

\section{REFERENCES}

1. J. P. Kofoed, "Model Testing of the Wave Energy Converter Seawave Slot-Cone Generator," Hydraul. Coast. Eng. No .18, 2005.

2. B. J. Larsen and J. P. Kofoed, "Model Test Setup and Program for Experimental Estimation of Surface Loads of the SSG Kvitsøy Pilot Plant from Extreme Wave Conditions," Civ. Eng., no. phase 4, 2005.

3. J. P. Kofoed, "Wave Overtopping of Marine Structures - Utilization of Wave Energy," PhD Thesis, Aalborg University, 2002.

4. J. P. Kofoed, "Model study of overtopping of marine structures for a wide range of geometric parameters," in The 27th International Conference on Coastal Engineering: ICCE 2000, 2000.

5. L. Margheritini, D. Vicinanza, and P. Frigaard, "Sea Slot Cone Generator Overtopping Performance in 3D Conditions," in ISOPE-International Offshore and Polar Engineering Conference. Proceedings, 2008, p. 18.
6. L. Margheritini, L. Victor, J. P. Kofoed, and P. Troch, "Geometrical Optimization for Improved Power Capture of Multi-level Overtopping Based Wave Energy Converters," Isope, vol. 1. International Society of Offshore and Polar Engineers, Osaka, Japan, pp. 339-344, 01-Jul-2009.

7. M. Buccino, D. Vicinanza, F. Ciardulli, M. Calabrese, and J. Peter, "Wave Pressures and Loads on a Small Scale Model of the Svåheia SSG pilot project," in 9th European Wave and Tidal Energy Conference, 2011, pp. 1-7.

8. L. Margheritini, V. Stratigaki, and P. Troch, "Geometry Optimization of an Overtopping Wave Energy Device Implemented into the New Breakwater of the Hanstholm Port Expansion," in International Offshore and Polar Engineering Conference, 2012, pp. 593-600.

9. J. W. Van der Meer and W. Janssen, "Wave run-up and wave overtopping at dikes and revetments," 1994.

10. J. . de Wall and J. . van der Meer, "Wave runup and overtopping on coastal structures," in Proceedings of the twenty-third coastal engineering conference, 1992, pp. 1758-1771.

11. J. W. Van der Meer, Wave run-up and overtopping. Dikes and Revetments: Design, Maintenance and Safety Assessment, ed. KW Pilarczyk (AA Balkema, Rotterdam, The Netherlands). A.A. Balkema, 1998.

12. L. Méhauté, R. C. Y. Koh, and L. Hwang, "A Synthesis on Wave Run-Up," J. Waterw. Harb. Div., vol. 94, no. 1, pp. 77-92, 1968.

13. L. Margheritini, D. Vicinanza, and P. Frigaard, "SSG wave energy converter: Design, reliability and hydraulic performance of an innovative overtopping device," Renew. Energy, vol. 34, no. 5, pp. 1371-1380, May 2009.

14. D. Vicinanza, P. Contestabile, Q. H. N. Jørgen, and T. Lykke Andersen, "Innovative rubble mound breakwaters for overtopping wave energy conversion," Coast. Eng., vol. 88, pp. 154-170, Jun. 2014.

15. I. Flow Science, FLOW-3D Documentation Release 10.1.0. 2012.

16. L. Franco, J. Geeraerts, R. Briganti, M. Willems, G. Bellotti, and J. De Rouck, "Prototype measurements and small-scale model tests of wave overtopping at shallow rubble-mound breakwaters: the Ostia-Rome yacht harbour case," Coast. Eng., vol. 56, no. 2, pp. 154-165, 2009.

17. B. MacVicar and J. Best, "A flume experiment on the effect of channel width on the perturbation and recovery of flow in straight pools and riffles with smooth boundaries," J. Geophys. Res. Earth Surf., vol. 118, no. 3 , pp. $1850-1863,2013$.

\section{AUTHORS PROFILE}

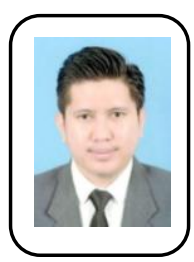

Muhammad Adli Bin Mustapa (Dr.), $\mathrm{PhD}$ in Mechanical Engineering, Publication: Wave energy device and breakwater integration: A review., Numerical Simulation of the Ramp Design of a Multistage Overtopping Wave Energy Breakwater Hybrid Device., Stability, Seakeeping And Safety Assessment Of Smal Fishing Boats Operating In Southern Coast Of Peninsular Malaysia., Numerical Study of Multistage Overtopping Wave Energy Device., and Combined Ocean Renewable Energy System (CORES) for Islandic Area on Malaysian Seas, Research work: Gravitation Water Vortex Power Plant., Environmental Impact of Tourist Boats Wake Wash in Kilim River., Development Of Combined Ocean Renewable Energy System Prototype (CORES)., and New Concept of Wave Energy- Breakwater Device.

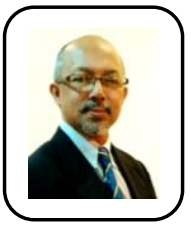

Omar Bin Yaakob (Professor), $\mathrm{PhD}$ in Seakeeping Design, Publications: Satellite-based wave data and wave energy resource assessment for South China Sea., Optimisation of a Waste Heat Exchanger for Ballast Water Treatment., Investigation of hydroelastic effect in analysis of high-speed craft., Analysis of noise behaviour for marine propellers under cavitating and noncavitating conditions., Novel approach of bidirectional diffuser-augmented channels system for enhancing hydrokinetic power generation in channels., Operation, Performance and Cost Analysis of Low Head Micro Hydropower Turbines for Rural and remotes Area: A Review., A Review of Developments in Ballast Water Management., An analysis of shipboard waste heat availability for ballast water treatment., Parametric 


\section{Numerical Simulation of the Overtopping-Ramp Design of a Multistage Overtopping Wave Energy Breakwater Hybrid Device}

Study of A Low Wake-Wash Inland Waterways Catamaran., Parametric study of a low wake-wash inland waterways catamaran., Computational Simulation of Current Forces on Floating Production Storage and Offloading in Irregular Waves., Proposal of use of diesel engine and surface-piercing propeller to achieve fuel savings for inshore fishing boats, Journal of Marine Science and Application., Numerical Investigation of Curvature and Torsion Effects on Water Flow Field in Helical Rectangular Channels., Hydro Power and Turbine Systems Reviews., Development of Low Wake Wash Hull Form., CFD Validation for Efficient Gravitational Vortex Pool System., CFD Simulation of Water Gravitation Vortex Pool Flow for Mini Hydropower Plants., Comparison of Heat Exchanger Designs for Ship Ballast Water Heat Treatment System., Use of CFD to study the resistance of sprint master canoe., Design Verification of Heat Exchanger for Ballast Water Treatment., Design verification of heat exchanger for ballast water treatment., Field measurement of fishing boats generated waves., A Review on Micro Hydro Gravitational Vortex Power and Turbine Systems., Design of a New Low Cost ROV Vehicle., A Review on Micro Hydro Gravitational Vortex Power and Turbine Systems., The Promise of Marine Renewable Energy in Malaysia: Too Good To Be True?., Model Testing of an Ocean Wave Energy System for Malaysian Sea., Experimental Studies on Savonius-Type Vertical Axis Turbine For Low Marine Current Velocity., Comparison of conventional and helical savonius marine current turbine using computational fluid dynamic., Parametric study of a low wake-wash inland waterways catamaran and etc, Research work: naval architecture., ship design., hydrodynamics., marine transportation., management and operation., ocean renewable energy and marine environment, Membership: Fellow of Royal Institution of Naval Architects (FRINA), Associate of Malaysian Academy of Science (Assoc. A. Sc)., Chartered Engineer (C. Eng. United Kingdom), and Member of Malaysian Society for Engineering and Technology.

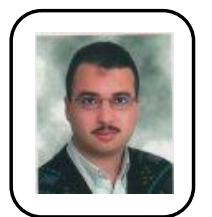

Yasser Mohamed Ahmed Abdel Razak (Associate Professor), PhD in Naval Arch. \& Marine Engineering, Publication: Operation, performance and economic analysis of low head micro-hydropower turbines for rural and remote areas: A review., Wave energy device and breakwater integration: A review., Numerical simulation for the free surface flow around a complex ship hull form at different Froude numbers., Influence of parent vessel dominancy on fluid dynamics of anterior communicating artery aneurysms., A review on micro-hydro gravitational vortex power and turbine systems., Simulation of free surface flow around a VLCC hull using viscous and potential flow methods., The adverse effects of flow-diverter stent-like devices on the flow pattern of saccular intracranial aneurysm models: computational fluid dynamics study., Performance study of ducted nozzle Savonius water turbine, comparison with conventional Savonius turbine., Validation study for Savonius vertical axis marine current turbine using CFD simulation., Global renewable energy and its potential in Malaysia: A review of Hydrokinetic turbine technology., CFD simulation of water gravitation vortex pool flow for mini hydropower plants., Effect of wing form on the hydrodynamic characteristics and dynamic stability of an underwater glider., Novel approach of bidirectional diffuser-augmented channels system for enhancing hydrokinetic power generation in channels., Experimental investigation of a wing-in-ground effect craft., Effect of foliar spray with active yeast extract on morphological, anatomical and yield characteristics of kidney bean., CFD validation for efficient gravitational vortex pool system., Botanical studies on Phaseolus vulgaris L. I-morphology of vegetative and reproductive growth., Numerical study for the use of different nozzle shapes in microscale channels for producing clean energy., Determining Ship Resistance Using Computational Fluid Dynamics (CFD)., Review of micro-bubble ship resistance reduction methods and the mechanisms that affect the skin friction on drag reduction from 1999 to 2015., Design of a new low cost ROV vehicle., Three-dimensional numerical analysis of restricted water effects on the flow pattern around hull and propeller plane of LNG ship., Comparison of conventional and helical savonius marine current turbine using computational fluid dynamics., Model testing of an ocean wave energy system for malaysian sea., Parametric study of a low wake-wash inland waterways catamaran., Parametric study of a low wake-wash inland waterways catamaran., Numerical Simulation for the Flow around the Hull of the DTMB Model 5415 at Different Speeds., Hydro power and turbine systems reviews., CFD Simulation for Stratified Oil-Water Two-Phase Flow in a Horizontal Pipe., Parametric Study for Savonius Vertical Axis Marine Current Turbine using CFD Simulation. 